\title{
Somatostatin and CXCR4 chemokine receptor expression in hepatocellular and cholangiocellular carcinomas: tumor capillaries as promising targets
}

Daniel Kaemmerer ${ }^{1 \dagger}$, Robin Schindler ${ }^{2 \dagger}$, Franziska Mußbach $^{3 \dagger}$, Uta Dahmen $^{3}$, Annelore Altendorf-Hofmann ${ }^{3}$, Olaf Dirsch ${ }^{4}$, Jörg Sänger ${ }^{5}$, Stefan Schulz ${ }^{2}$ and Amelie Lupp ${ }^{2^{*}}$

\begin{abstract}
Background: Hepatocellular (HCC) and cholangiocellular carcinomas (CCC) display an exceptionally poor prognosis. Especially for advanced disease no efficient standard therapy is currently available. Recently, somatostatin analogs have been evaluated for the treatment of HCC, however, with contradictory results. Besides, for both malignancies the chemokine receptor CXCR4 has been discussed as a possible new target structure.

Methods: Expression of somatostatin receptor (SSTR) subtypes 1, 2A, 3, 4, and 5, and of CXCR4 was evaluated in a total of 71 HCCS and 27 CCCs by immunohistochemistry using well-characterized novel monoclonal antibodies.

Results: In HCC tumor cells, frequency and intensity of expression of SSTRs and CXCR4 were only low. CXCR4 was present in about $40 \%$ of the HCCs, although at a low intensity. SSTR5, SSTR2, and SSTR3 were detected in about $15 \%, 8 \%$, and $5 \%$ of the HCC tumors, respectively. SSTR and CXCR4 expression was much higher in CCC than in HCC. CXCR4 and SSTR1 were present in 60\% and 67\% of the CCC samples, respectively, followed by SSTR2 and SSTR5, which were detected in $30 \%$ and $11 \%$ of the tumors, respectively. Most notably, CXCR4 was intensely expressed on the tumor capillaries in about $50 \%$ of the HCCs and CCCS. CXCR4 expression on tumor vessels was associated with poor patient outcomes.
\end{abstract}

Conclusions: CCC, but not HCC, may be suitable for SSTR-based treatments. Because of the predominant expression of SSTR1, pan-somatostatin analogs should be preferred. In both HCC and CCC, indirect targeting of tumors via the CXCR4-positive tumor capillaries may represent a promising additional therapeutic strategy.

Keywords: Somatostatin receptors, Chemokine receptor, CXCR4, Hepatocellular carcinoma, Cholangiocellular carcinoma

\section{Background}

Hepatocellular carcinomas (HCCs) account for $90 \%$ of primary liver tumors and are the fifth most common malignoma diagnosed in men, the seventh most common malignoma diagnosed in women, and the third leading cause of cancer-related death worldwide. The highest incidence is reported for China, Africa, and

\footnotetext{
* Correspondence: Amelie.Lupp@med.uni-jena.de

${ }^{\dagger}$ Equal contributors

${ }^{2}$ Institute of Pharmacology and Toxicology, Jena University Hospital, Friedrich Schiller University Jena, Drackendorfer Str. 1, D-07747 Jena, Germany

Full list of author information is available at the end of the article
}

South-East Asia ( $>20$ cases per 100,000 persons), whereas HCCs are relatively uncommon in Western countries ( $<5$ cases per 100,000 persons) $[1,2]$. On the whole, HCC displays a very poor prognosis, with an overall median survival of 11 months and an overall 1year survival rate of less than $50 \%[3,4]$. Especially for advanced disease, there is no efficient standard therapy currently available. The only curative treatment options are liver resection and liver transplantation, providing 5year survival rates of up to $70 \%$. However, only a minority of patients $(<20 \%)$ is suited for such interventions because of tumor expansion, metastatic disease, severe 
cirrhosis, and impaired liver function [1, 5]. Further treatment modalities, especially for advanced-stage disease, comprise transarterial chemoembolization (TACE), ethanol injection, radio-frequency or microwave ablation, and selective internal radiation therapy (SIRT). With respect to systemic pharmacotherapy, which currently consists only of sorafenib, a multi-tyrosine kinase inhibitor with antiangiogenic and antiproliferative properties, a significant therapeutic benefit has been shown in patients with advanced HCC, whereas "classical" chemotherapy is ineffective in such patients $[1,5]$. However, sorafenib rapidly loses efficacy in many cases $[6,7]$, because of additional mutations in the signal transduction cascades. Therefore, alternate (tyrosine) kinase inhibitors and combined therapy regimens, in addition to other targeted therapies, are currently under investigation for the treatment of advanced HCC [6].

Intrahepatic cholangiocarcinomas (CCCs) are the second most common type of primary liver tumor and account for about $10 \%$ of all primary malignancies of the liver $[1,8]$. The prognosis for CCC is exceptionally poor, such as the best outcomes, seen in patients who are candidates for surgery, show a 5-year survival rate of $30.6 \%$ and a median overall survival of 27 months following diagnosis [9]. Because of high recurrence rates, liver transplantation is not recommended in CCC. Liver resection represents the only curative treatment option; however, CCC is diagnosed relatively late in the majority of patients, making curative resection no longer possible [1]. Compared with the best supportive care, systemic chemotherapy with gemcitabine and cisplatin significantly prolongs survival of patients with inoperable tumors, making it the treatment standard for advanced disease, although overall benefits are not very pronounced. Therefore, other targeted therapies are urgently needed also for CCC $[10,11]$.

Among the new molecular target structures that have been evaluated for treatment of HCC are the somatostatin receptor (SSTR) subtypes SSTR1 - SSTR5, which in immunohistochemical studies have been shown to be present in a substantial fraction of tumor samples, although quite divergent expression intensities and receptor expression profiles have been described [12-17]. Since data obtained from in vitro experiments using hepatoma cell lines and from different HCC animal models were also very promising [18-24], a number of clinical investigations was conducted to investigate the prognostic and therapeutic value of SSTRs. Apart from a few promising studies [16, 25-28], most trial outcomes were quite discouraging (see e.g. [29-36]). The reasons for these discrepancies are still unknown and remain to be elucidated.

The chemokine receptor CXCR4 represents another promising molecular target structure for tumor diagnosis and therapy. Overexpression of this receptor has been observed in more than 20 different tumor entities and many studies demonstrated that increased CXCR4 expression is associated with rapid tumor progression, high invasiveness, early metastasis, and poor patient outcomes [37]. With respect to HCC, however, the data are contradictory. In the majority of studies, CXCR4 expression was higher in tumors than in normal liver tissues and was correlated with tumor aggressiveness and reduced patient survival [38-44]. Other immunohistochemical or PCR analyses demonstrated either no difference $[45,46]$ or even lower CXCR4 expression in tumors $[47,48]$ compared with normal tissues. Therefore, further investigations in the role of CXCR4 in HCC are necessary.

In contrast to HCC, CCCs have not been evaluated for SSTR expression so far and only one study has examined CXCR4 expression in CCC [49], demonstrating correlations between CXCR4 expression and tumor progression, metastasis, and poor patient outcomes.

The vast majority of the existing immunocytochemical and immunohistochemical data on SSTR and CXCR4 expression in $\mathrm{HCC}$ and $\mathrm{CCC}$ was obtained using polyclonal antibodies from different commercial and noncommercial sources, which may explain the divergent results obtained. Additionally, in many cases (especially with respect to CXCR4) even a nuclear staining for these membrane-bound G-protein-coupled receptors has been described, suggesting non-specific antibody interactions. Therefore, the aim of the present study was to reevaluate the expression of SSTRs and CXCR4 in a large set of formalin-fixed, paraffin-embedded HCC and CCC samples by using well-characterized novel rabbit monoclonal antibodies. These antibodies were generated and extensively characterized by our group [50-54] and have also been validated by other authors (e.g. $[55,56])$. In parallel and to re-evaluate SSTR and CXCR4 expression in hepatoma cell lines, samples of three commonly used human hepatoblastoma (HepG2) and HCC cell lines (Hep3B, and $\mathrm{HuH}-7)$ as well as of the small cell lung cancer cell line NCI-H69 and the pancreatic neuroendocrine tumor cell line BON-1 (as positive controls) were embedded in paraffin blocks and stained for the different SSTRs and CXCR4.

\section{Methods}

\section{Tumor specimens}

A total of 171 archived, formalin-fixed, paraffinembedded tumor samples from 98 patients (in detail, $78 \times 1,2 \times 2,7 \times 3,3 \times 4,1 \times 5,2 \times 6,3 \times 7,1 \times 8$, and $1 \times$ 10 samples per patient) with histologically verified $\mathrm{HCC}$ or $\mathrm{CCC}$ were included in the present investigation. Of the 98 tumors investigated, 71 (72\%) were HCC and 27 (28\%) were CCC. Samples were provided by the Institute of Pathology and Cytology Bad Berka, Bad Berka, 
Germany, and by the Institute of Pathology, Jena University Hospital, Jena, Germany. The tumors had been surgically removed between 2007 and 2014 either at the Department of General and Visceral Surgery, Zentralklinik Bad Berka, Bad Berka, Germany, or at the Department of General, Visceral and Vascular Surgery, Jena University Hospital, Jena, Germany. The corresponding clinical data were gathered from patient records.

\section{Cytoblocks}

HepG2, Hep3B, HuH-7, NCI-H-69, and BON-1 cells (DSMZ, Braunschweig, Germany) were grown in $75 \mathrm{~cm}^{2}$ culture flasks to a confluency of $80 \%$. Cells were washed once with phosphate-buffered saline and transferred into $10 \%$ buffered formalin (J.T.Baker, Deventer, The Netherlands) for $2 \mathrm{~h}$. After centrifugation for $10 \mathrm{~min}$ at $3500 \times g$, the supernatant was removed, and $1 \mathrm{ml}$ human pool plasma was added to the cell samples. After brief vortexing, $100 \mu \mathrm{l}$ human fibrinogen $(50-70 \%$ protein; $\geq 80 \%$ clottable; Sigma-Aldrich Chemie $\mathrm{GmbH}$, Steinheim, Germany) was added to each sample, and the samples were vortexed again. The resulting clots were placed for another $24 \mathrm{~h}$ in $10 \%$ buffered formalin and embedded in paraffin blocks.

\section{Immunohistochemistry}

From the paraffin blocks, $4 \mu \mathrm{m}$ sections were cut, floated onto adhesive-coated slides and subjected to immunostaining by means of an indirect peroxidase labeling method as described recently [57]. Except for SSTR4, rabbit monoclonal antibodies (hybridoma cell culture supernatants) were used to detect SSTRs and CXCR4 (Table 1; [57]). As positive controls, sections from human pancreas (islets; SSTR1, SSTR2, SSTR3, SSTR5), lymph nodes (germinal centers; SSTR2, SSTR5, CXCR4, Ki-67), and human cortex (SSTR4) were used (Additional file 1:
Figure S1). As negative control, the primary antibody was either omitted or adsorbed for $2 \mathrm{~h}$ at room temperature with $10 \mu \mathrm{g} / \mathrm{ml}$ of the peptide used for immunizations of the rabbits [57]. Additional immunostainings were performed with monoclonal mouse antibodies against the proliferation marker Ki-67 (Table 1).

Staining for the receptors was evaluated by means of the semiquantitative Immunoreactivity Score (IRS) according to Remmele and Stegner [58] and as described recently [57]: The percentage of positively stained tumor cells quantified in five gradations (no positive cells [0], $<10 \%$ positive cells [1], $10-50 \%$ positive cells [2], 51$80 \%$ positive cells [3], $>80 \%$ positive cells [4]) was multiplied by the staining intensity, which was assessed in four scales (no staining [0], mild staining [1], moderate staining [2], strong staining [3]). Finally, IRS values extending from 0 to 12 were obtained. In case of more than one tumor slide per patient, an arithmetic mean was calculated from the IRS values of these slides. Only tumor samples with IRS values $\geq 3$ were considered positive [57]. IRS values were further classified as follows: 02 , negative/no expression; $3-5$, low expression; 6-8, moderately strong expression; 9-12, strong expression. Staining of the tumor vessels for SSTRs and CXCR4 was evaluated separately by determining the percentage of positive vessels in relation to all vessels. Tumors with $\geq 10 \%$ of vessels being stained for the respective receptor were considered positive [57]. With respect to Ki-67 staining, the percentage of positive nuclei was determined. All immunohistochemical stainings were evaluated by two independent blinded investigators (RS, AL). In case of discrepant scores, final decision was achieved by consensus.

\section{Statistics}

For graphical data processing and statistical analysis, the IBM SPSS statistics program version 22.0.0.0 was used.

Table 1 Antibodies used for immunohistochemical stainings

\begin{tabular}{|c|c|c|c|c|c|}
\hline Antibody & Clone & Type & Epitope & Supplier & Dilution \\
\hline SSTR1 & UMB-7 & rabbit monoclonal & $\begin{array}{l}\text { ENLESGGVFRNGTCTSRITTL } \\
\text { (residues 377-391) }\end{array}$ & Epitomics, Burlingame, CA & $1: 25$ \\
\hline SSTR2 & UMB-1 & rabbit monoclonal & $\begin{array}{l}\text { ETQRTLLNGDLQTSI } \\
\text { (residues 335-369) }\end{array}$ & Epitomics, Burlingame, CA & $1: 10$ \\
\hline SSTR3 & UMB-5 & rabbit monoclonal & $\begin{array}{l}\text { QLLPQEASTGEKSSTMRISYL } \\
\text { (residues 398-418) }\end{array}$ & Epitomics, Burlingame, CA & $1: 20$ \\
\hline SSTR4 & 4802 & rabbit polyclonal & $\begin{array}{l}\text { CQQEALQPEPGRKRIPLTRTTIF } \\
\text { (residues 366-388) }\end{array}$ & Gramsch, Schwabhausen, Germany & $0.1 \mu \mathrm{g} / \mathrm{ml}$ \\
\hline SSTR5 & UMB-4 & rabbit monoclonal & $\begin{array}{l}\text { QEATPPAHRAAANGLMQTSKL } \\
\text { (residues 344-364) }\end{array}$ & Epitomics, Burlingame, CA & $1: 10$ \\
\hline CXCR4 & UMB-2 & rabbit monoclonal & $\begin{array}{l}\text { KGKRGGHSSVSTESESSSFHSS } \\
\text { (residues 338-359) }\end{array}$ & Epitomics, Burlingame, CA & $1: 2$ \\
\hline Ki-67 & MIB-1 & mouse monoclonal & & DAKO, Hamburg, Germany & $1: 75$ \\
\hline
\end{tabular}


Expression levels (IRS values) of the SSTRs and of the CXCR4 in the HCC and CCC samples were presented as box plots, depicting the median value, the upper and lower quartile, minimum and maximum values, and outliers. The outliers were defined as follows: mild outliers (marked by circles): data that fall between 1.5 and 3 times above the upper quartile or below the lower quartile, respectively; extreme outliers (marked by asterisks): data that fall more than 3 times above the upper quartile or below the lower quartile, respectively. Since these outliers could not be attributed to technical errors (some stains were repeated for control), but may reflect the expression profile of a yet undefined subset of patients, they were not excluded from the statistical analyses.

Because the data were not normally distributed (Kolmogorov-Smirnov test), for the statistical analyses Mann-Whitney test, Kendall's $\tau$-b test, Chi-Square test, and Spearman's rank correlation were performed. For survival analysis, the Kaplan-Meier method with a log-rank test was used. $P$ values $\leq 0.05$ were considered statistically significant. For the correlation calculations with the clinical data, correction for multiple comparisons was performed by using the BonferroniHolm procedure.

\section{Results}

\section{Patient characteristics}

Overall, tumors from 80 male (82\% of the cases) and 18 female patients ( $18 \%$ of the cases) were evaluated in the present investigation. Of the $71 \mathrm{HCC}$ patients, 57 were male ( $80 \%$ of the cases) and 14 female $(20 \%$ of the cases), of the 27 CCC patients 23 were male ( $85 \%$ of the cases) and 4 were female (15\% of the cases) (Table 2 ). Mean age of the HCC patients at diagnosis was 63.9 years (median: 65 years; range: $25-87$ years) and that of the CCC patients 65.5 years (median: 66 years; range: 45-79 years) (Table 2). There was no significant difference between $\mathrm{HCC}$ and $\mathrm{CCC}$ patients with respect to patient age and gender.

The median survival was 18 months for HCC patients (minimum: 0 months; maximum: 73 months), and 11 months for CCC patients (minimum: 2 months; maximum: 56 months) (Table 2). Twenty-four (34\%) of the HCC patients and $8(30 \%)$ of the CCC patients had stage I disease, 20 (28\%) of the HCC patients and 13 (48\%) of the CCC patients had stage II disease, 18 (26\%) of the HCC patients and 1 (4\%) of the CCC patients had stage IIIA disease, $1(1 \%)$ of the HCC patients had had stage IIIB disease (CCC: $0 \%), 3$ (11\%) of the CCC patients had stage IVA disease (HCC: $0 \%$ ), and 8 (11\%) of the HCC patients and $2(7 \%)$ of the CCC patients had stage IVB disease (Table 2). With respect to histological grading, $13(18 \%)$ of the HCC and 1 (4\%) of the CCC were grade $1,43(61 \%)$ of the HCC and $18(66 \%)$ of the CCC were
Table 2 Patient characteristics. HCC: hepatocellular carcinoma; CCC: cholangiocellular carcinoma

\begin{tabular}{|c|c|c|c|}
\hline & $\mathrm{HCC}$ & $\mathrm{CCC}$ & All tumors \\
\hline Total no. & 71 & 27 & 98 \\
\hline \multicolumn{4}{|l|}{ Sex } \\
\hline male & 57 & 23 & 80 \\
\hline female & 14 & 4 & 18 \\
\hline \multicolumn{4}{|l|}{ Age (years) } \\
\hline mean & 63.9 & 65.5 & 64.4 \\
\hline median & 65.0 & 66.0 & 65 \\
\hline \multicolumn{4}{|c|}{ Survival (months) } \\
\hline mean & 20.3 & 14.7 & 18.8 \\
\hline median & 18.0 & 11.0 & 15.0 \\
\hline \multicolumn{4}{|l|}{ Stage (n) } \\
\hline I & 24 [34\%] & 8 [30\%] & 32 [33\%] \\
\hline$\|$ & 20 [28\%] & 13 [48\%] & 33 [34\%] \\
\hline$\| I A$ & 18 [26\%] & 1 [4\%] & 19 [19\%] \\
\hline$\||| B$ & 0 [0\%] & 0 [0\%] & 0 [0\%] \\
\hline IIIC & 1 [1\%] & 0 [0\%] & 1 [1\%] \\
\hline IVA & 0 [0\%] & 3 [11\%] & 3 [3\%] \\
\hline IVB & 8 [11\%] & 2 [7\%] & 10 [10\%] \\
\hline \multicolumn{4}{|l|}{ Grading (n) } \\
\hline G1 & 13 [18\%] & 1 [4\%] & 14 [14\%] \\
\hline $\mathrm{G} 2$ & 43 [61\%] & 18 [66\%] & 61 [62\%] \\
\hline G3 & 15 [21\%] & 7 [26\%] & 22 [23\%] \\
\hline G4 & 0 [0\%] & 1 [4\%] & $1[1 \%]$ \\
\hline
\end{tabular}

grade 2, $15(21 \%)$ of the HCC and $7(26 \%)$ of the CCC were grade 3 , and $1(4 \%)$ of the $\mathrm{CCC}$ were grade 4 (HCC: $0 \%$ ) (Table 2). Of the $71 \mathrm{HCC}$ patients 54 (76\%) had liver cirrhosis. Of these patients with liver cirrhosis only 2 patients each had a history of hepatitis B viral infection or of an autoimmune hepatitis. From 8 patients the etiology of liver cirrhosis was not known/not reported in the patient files. All other patients suffered from alcohol-related liver disease. None of the CCC patients had liver cirrhosis and there was also no history of hepatitis $\mathrm{B}$ or $\mathrm{C}$, autoimmune or alcoholic liver disease reported with these patients.

\section{Somatostatin and CXCR4 chemokine receptor expression in tumor samples}

Only few of the HCC tumors displayed SSTR-positive or CXCR4-positive staining (i.e. an IRS value $\geq 3$ ). Also median intensities of SSTR and CXCR4 expression (calculated from all IRS values ranging from 0 to 12) in the HCCs were only low (Fig. 1a and b; Table 3). CXCR4, the most prominent receptor in the HCC samples, was present in about $40 \%$ of the cases, but only 

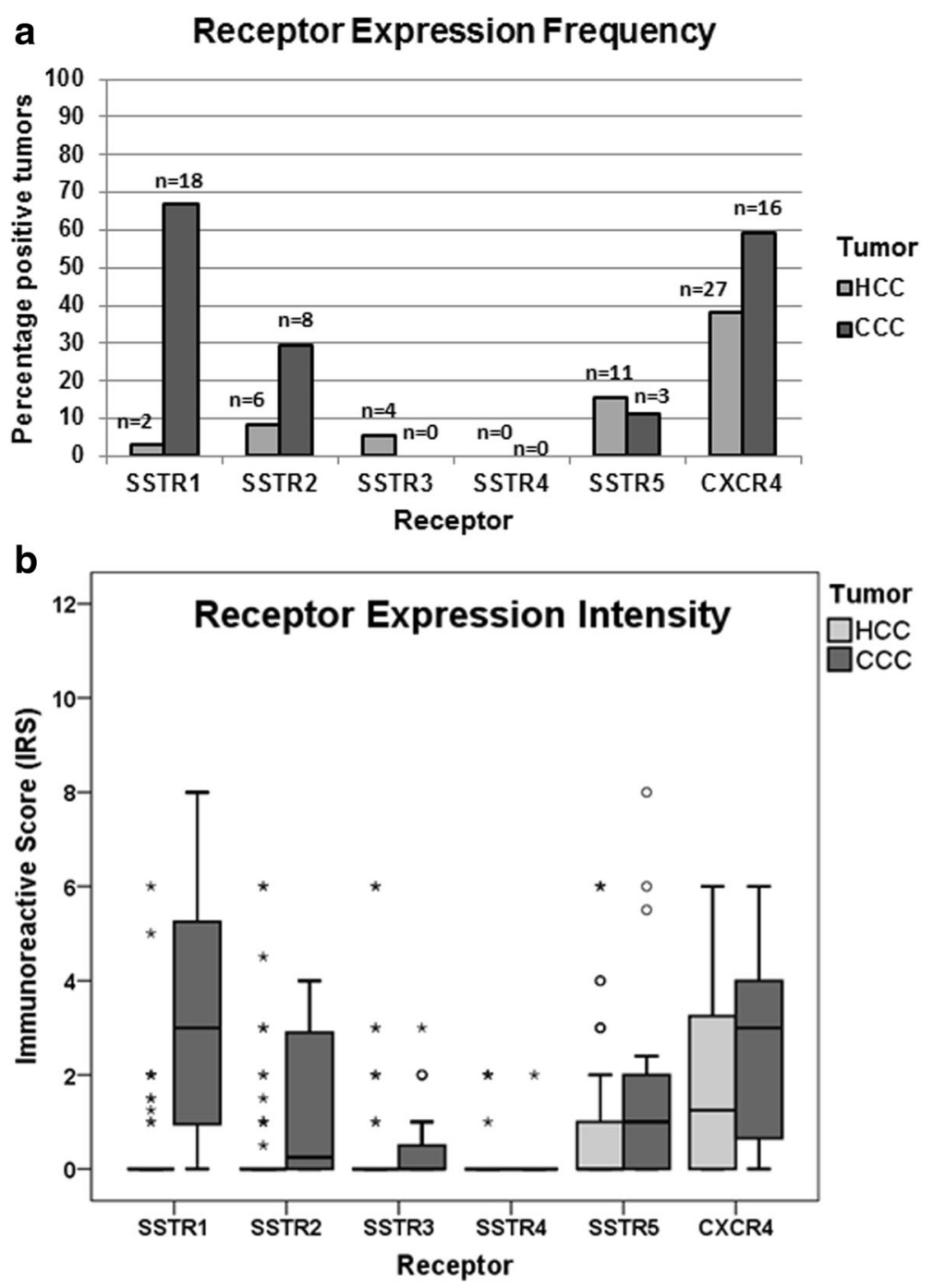

Fig. 1 Expression profile of the different somatostatin receptor (SSTR) subtypes and of the CXCR4 chemokine receptor in hepatocellular (HCC) and cholangiocellular (CCC) carcinomas. a Percentage and number of positive cases for the different SSTRs and for CXCR4. Tumors were only considered positive at IRS values $\geq 3$. $\mathbf{b}$ Box plots of the expression levels (IRS values) of SSTRs and CXCR4 in HCC and in CCC. Depicted are median values, upper and lower quartiles, minimum and maximum values, as well as outliers. Outliers are defined as follows: circles: mild outliers; data that fall between 1.5 and 3 times above the upper quartile or below the lower quartile; asterisks: extreme outliers; data that fall more than 3 times above the upper quartile or below the lower quartile

at a very low intensity (median IRS: 1.25 ). Only four tumor samples (6\% of the cases) displayed moderately strong CXCR4 expression with an IRS value $\geq 6$. SSTR5, SSTR2, SSTR3, and SSTR1 were detected with IRS values $\geq 3$ in about $15 \%, 8 \%, 6 \%$, and $3 \%$ of the HCC tumors, respectively. No SSTR4 positivity was observed (Table 3). Median expression intensity for all SSTRs in the HCC samples amounted to an IRS value of 0 (Table 3). Eight (10\%) of the patients displayed moderately strong (IRS value $\geq 6$ ) SSTR expression in their HCC samples (SSTR1, 1 patient; SSTR2, 2 patients; SSTR3, 2 patients; SSTR5, 3 patients; no overlapping staining).
Compared with the HCC samples, a larger fraction of the CCC samples displayed SSTR or CXCR4 staining (Fig. 1a and b; Table 3). CXCR4 was present with IRS values $\geq 3$ in $60 \%$ of the CCC samples. SSTR 1 was detected in $67 \%$ of the CCC samples. In both cases, the median IRS value was 3, which is, however, still low. SSTR2 and SSTR5 were expressed in 30\% and 11\% of the CCC samples, respectively. None of the CCC samples showed staining for SSTR3 or SSTR4. The median IRS value for SSTR5 was 1, whereas scores for SSTR2, SSTR3 and SSTR4 were below that level (Table 3). A total of eight CCC samples (30\%) displayed moderately strong (IRS value $\geq 6$ ) SSTR expression (7 samples for 
Table 3 Receptor expression data

\begin{tabular}{|c|c|c|}
\hline & $\mathrm{HCC}$ & CCC \\
\hline Total no. & 71 & 27 \\
\hline mean IRS & 0.41 & 3.50 \\
\hline median IRS & 0 & 3.0 \\
\hline minimum/maximum IRS & $0 / 6$ & $0 / 8$ \\
\hline positive cases $(n)^{a}$ & $2[3 \%]$ & 18 [67\%] \\
\hline \multicolumn{3}{|l|}{ SSTR2 } \\
\hline mean & 0.53 & 1.16 \\
\hline median & 0 & 0.25 \\
\hline minimum/maximum IRS & $0 / 6$ & $0 / 4$ \\
\hline positive cases $(n)^{a}$ & 6 [8\%] & 8 [30\%] \\
\hline \multicolumn{3}{|l|}{ SSTR3 } \\
\hline mean & 0.39 & 0.48 \\
\hline median & 0 & 0 \\
\hline minium/maximum IRS & $0 / 6$ & $0 / 3$ \\
\hline positive cases $(n)^{a}$ & $4[6 \%]$ & $0[0 \%]$ \\
\hline \multicolumn{3}{|l|}{ SSTR4 } \\
\hline mean & 0.15 & 0.07 \\
\hline median & 0 & 0 \\
\hline minium/maximum IRS & $0 / 2$ & $0 / 2$ \\
\hline positive cases $(n)^{a}$ & 0 [0\%] & $0[0 \%]$ \\
\hline \multicolumn{3}{|l|}{ SSTR5 } \\
\hline mean & 0.81 & 1.52 \\
\hline median & 0 & 1.00 \\
\hline minium/maximum IRS & $0 / 6$ & $0 / 8$ \\
\hline positive cases $(n)^{a}$ & 11 [15\%] & 3 [11\%] \\
\hline cases with microvessel positivity $(n)^{b}$ & 24 [34\%] & 12 [44\%] \\
\hline \multicolumn{3}{|l|}{ CXCR4 } \\
\hline mean & 1.76 & 2.70 \\
\hline median & 1.25 & 3.00 \\
\hline minium/maximum IRS & $0 / 6$ & $0 / 6$ \\
\hline positive cases $(n)^{a}$ & 27 [38\%] & 16 [60\%] \\
\hline cases with microvessel positivity $(n)^{b}$ & 35 [50\%] & $15[56 \%]$ \\
\hline
\end{tabular}

HCC hepatocellular carcinoma, CCC cholangiocellular carcinoma, IRS Immunoreactive Score; a positivity for a receptor was adopted at an IRS value $\geq 3$; ${ }^{\text {b tumors with }} \geq 10 \%$ of the vessels being stained for the respective receptor were considered positive

SSTR1, 3 samples for SSTR5). In two of the SSTRpositive tumors, both SSTR1 and SSTR5 were moderately co-expressed. Three $(11 \%)$ of the CCC samples displayed moderately strong CXCR4 expression.

Comparing relative receptor expression intensities between the two tumor entities, CCCs showed significantly higher intensities of expression of SSTR1, SSTR2, SSTR5, and CXCR4 than HCCs (Fig. 2).

Regarding the most common receptor expression profiles (threshold for positive staining at IRS values $\geq 3$ ), most of the HCC samples were negative for all of the receptors ( $n=33 ; 46 \%$ of the cases). Nineteen of the HCC samples stained positive only for CXCR4, and four of the HCCs displayed double-staining for both SSTR5 and CXCR4. Nine of the HCC samples were positive for a single SSTR: three each for SSTR2, SSTR3, and SSTR5. Most of the CCC samples ( $n=9 ; 33 \%$ of the cases) stained positive for both SSTR1 and CXCR4. Six of the CCC samples were negative for all of the receptors. Three of the CCC samples were positive for both SSTR1 and SSTR2.

In HCC, there was a significant correlation between the expression intensity of SSTR1 and the IRS values of SSTR4, SSTR5, and CXCR4 (Table 4). In CCC, there was a significant association between SSTR3 and SSTR5 expression intensities (Table 5). Additionally, there was a significant interrelationship between the proliferation marker Ki-67 and SSTR3 or SSTR5 expression intensities in HCC (SSTR3, $r=0.267, p=0.024$; SSTR5, $r=0.284, p=0.016)$ and SSTR2 or SSTR5 expression intensities in CCC (SSTR2, $r=0.389, p=0.045$; SSTR5, $r=0.390, p=0.044$ ).

As shown in Fig. 3, the monoclonal antibodies against SSTR1, SSTR2, SSTR3, SSTR5, and CXCR4 produced distinct immunostaining of the plasma membrane, but also of the cytoplasm of the HCC and CCC tumor cells. With the polyclonal anti-SSTR4 antibody, in contrast, only cytoplasmic immunostaining was observed (not shown). There was marked variation in staining intensity for all receptors within and among individuals, as depicted for SSTR2 in Figs. 4a-e, which show different photomicrographs taken from the same tumor slide. All in all, despite a few strongly stained tumor areas or groups of tumor cells, the tumors were largely negative in most cases, leading to low IRS values for each slide.

Independent from the tumor cells, many samples displayed strong staining for SSTR5 and CXCR4 on capillaries of the tumor stroma (Figs. $4 \mathrm{~g}$ and h). SSTR5 expression on tumor microvessels was observed in 34\% of the HCC samples and in $44 \%$ of the CCC samples. CXCR4 staining of the tumor microvessels was even detected in $50 \%$ of the HCC samples and in $56 \%$ of the CCC samples (Table 3).

Strong CXCR4 positivity was also seen in tumorinfiltrating lymphocytes (Fig. 4i). In the metastasiscontaining lymph node samples, SSTR2 and CXCR4 were strongly expressed in germinal centers of (activated) lymph follicles in close proximity to the tumor cells (Fig. 4f and j). The tumor-surrounding "normal" liver tissues were largely devoid of any SSTR or CXCR4 expression. Occasionally, SSTR5 staining of bile duct epithelia or CXCR4 positivity of Kupffer cells was observed. 

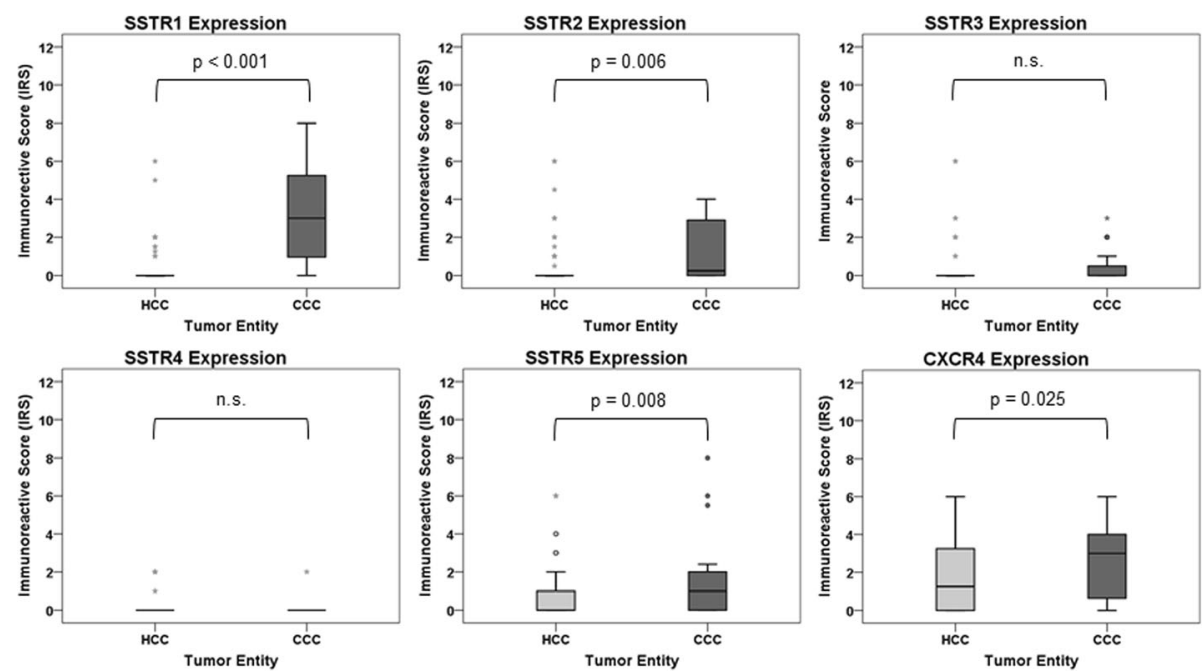

Fig. 2 Differential somatostatin receptor (SSTR) and CXCR4 expression in hepatocellular and cholangiocellular carcinomas. Box plots of the expression levels (IRS values) of SSTRs and CXCR4 in hepatocellular and cholangiocellular carcinomas. Depicted are median values, upper and lower quartiles, minimum and maximum values, as well as outliers. Outliers are defined as follows: circles: mild outliers; data that fall between 1.5 and 3 times above the upper quartile or below the lower quartile; asterisks: extreme outliers; data that fall more than 3 times above the upper quartile or below the lower quartile

\section{Correlation with clinical data}

In $\mathrm{HCC}$ a negative correlation between tumor diameter and SSTR2 expression intensity of the tumor cells was observed $\left(\mathrm{r}_{\mathrm{sp}}=-0.319, p=0.024\right)$. In CCC, on the other hand, tumor diameter was positively associated with intensity of CXCR4 expression of the tumor cells $\left(\mathrm{r}_{\mathrm{sp}}=\right.$ $0.762, p<0.001$ ). Here, CXCR4 positive tumors displayed a significantly larger diameter as compared to CXCR4

Table 4 Correlation between SSTR and CXCR4 expression intensities in hepatocellular carcinoma

\begin{tabular}{|c|c|c|c|c|c|}
\hline & SSTR2 & SSTR3 & SSTR4 & SSTR5 & CXCR4 \\
\hline \multicolumn{6}{|c|}{ SSTR1 } \\
\hline$r$ & 0.101 & -0.007 & 0.258 & 0.235 & 0.236 \\
\hline$p$ & 0.400 & 0.953 & 0.030 & 0.048 & 0.048 \\
\hline \multicolumn{6}{|c|}{ SSTR2 } \\
\hline$r$ & & 0.079 & 0.117 & 0.162 & 0.043 \\
\hline$p$ & & 0.511 & 0.331 & 0.178 & 0.724 \\
\hline \multicolumn{6}{|c|}{ SSTR3 } \\
\hline$r$ & & & 0.041 & 0.124 & 0.008 \\
\hline$p$ & & & 0.734 & 0.302 & 0.945 \\
\hline \multicolumn{6}{|c|}{ SSTR4 } \\
\hline$r$ & & & & 0.178 & 0.066 \\
\hline$p$ & & & & 0.138 & 0.584 \\
\hline \multicolumn{6}{|c|}{ SSTR5 } \\
\hline$r$ & & & & & 0.109 \\
\hline$p$ & & & & & 0.368 \\
\hline
\end{tabular}

negative ones (Mann-Whitney test: $p=0.018$ ). Apart from that, in both HCC and CCC, no significant correlation was seen between SSTR or CXCR4 expression intensities or positivity of the tumor cells and TNM classification, staging or grading of the tumors, presence or absence of cirrhosis or of vascular infiltration, presence of a solitary tumor or of multiple lesions, height of ASAT, ALAT or GGT serum values or of the tumor

Table 5 Correlation between SSTR and CXCR4 expression intensities in cholangiocellular carcinoma

\begin{tabular}{|c|c|c|c|c|c|}
\hline & SSTR2 & SSTR3 & SSTR4 & SSTR5 & CXCR4 \\
\hline \multicolumn{6}{|c|}{ SSTR1 } \\
\hline$r$ & 0.380 & 0.052 & -0.279 & 0.139 & 0.311 \\
\hline$p$ & 0.051 & 0.798 & 0.159 & 0.491 & 0.114 \\
\hline \multicolumn{6}{|c|}{ SSTR2 } \\
\hline$r$ & & 0.277 & 0.241 & 0.290 & -0.014 \\
\hline$p$ & & 0.161 & 0.226 & 0.142 & 0.944 \\
\hline \multicolumn{6}{|c|}{ SSTR3 } \\
\hline$r$ & & & 0.344 & 0.557 & 0.242 \\
\hline$p$ & & & 0.079 & 0.003 & 0.223 \\
\hline \multicolumn{6}{|c|}{ SSTR4 } \\
\hline r & & & & 0.195 & 0.140 \\
\hline$p$ & & & & 0.330 & 0.487 \\
\hline \multicolumn{6}{|c|}{ SSTR5 } \\
\hline$r$ & & & & & 0.142 \\
\hline$p$ & & & & & 0.480 \\
\hline
\end{tabular}




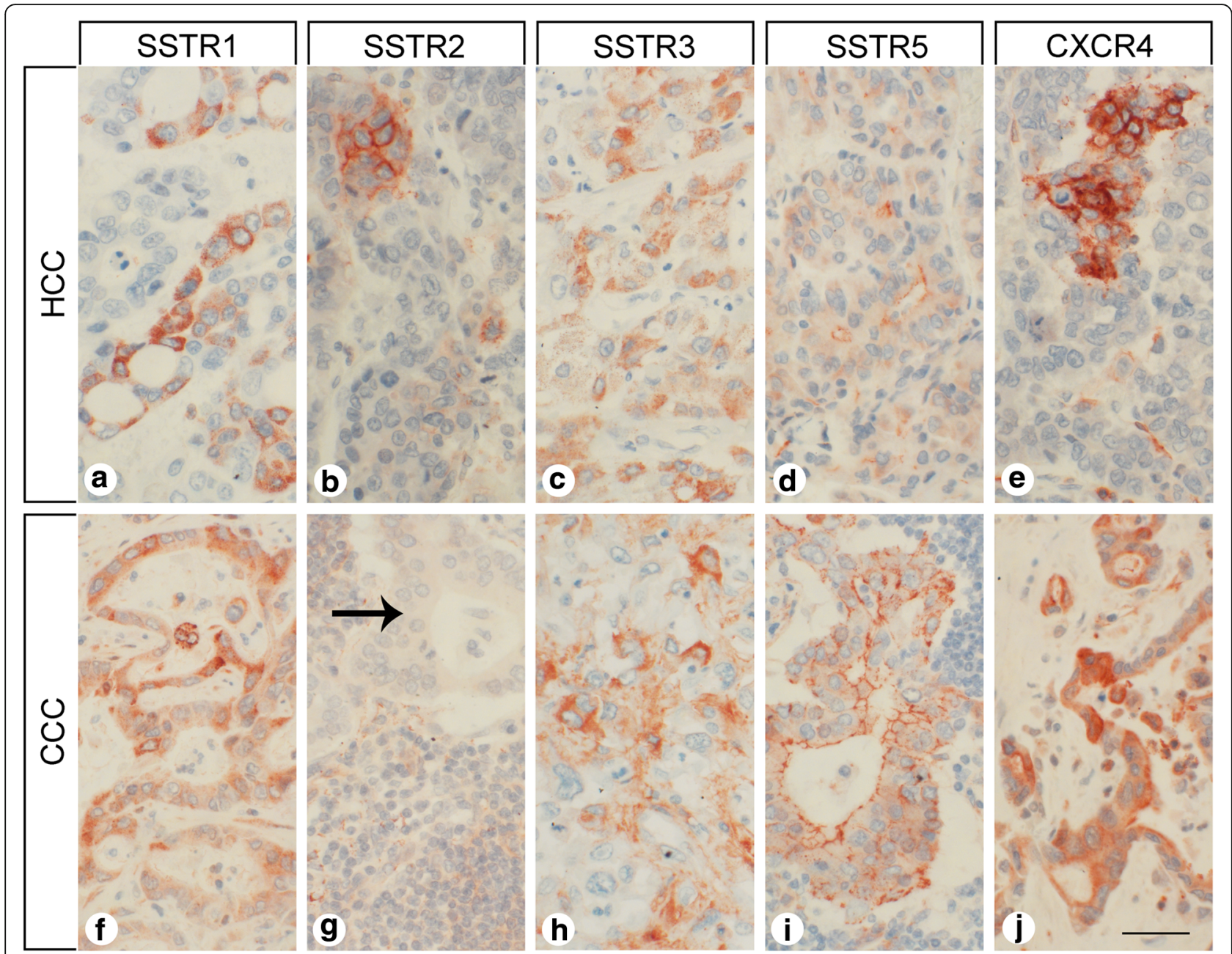

Fig. 3 Somatostatin receptor (SSTR) and CXCR4 expression pattern in hepatocellular and cholangiocellular carcinomas. Depicted are typical examples of staining patterns for SSTR1 ( $\mathbf{a}, \mathbf{f})$, SSTR2 (b, g), SSTR3 ( $\mathbf{c}, \mathbf{h})$, SSTR5 (d, i), and CXCR4 (e, j). Immunohistochemistry (red-brown color), counterstaining with hematoxylin; scale bar: 50 um; arrow in G: tumor cells. With the only exception of SSTR4, all receptors displayed both membranous and cytoplasmic expression

markers alpha fetoprotein (AFP) and CA19-9. There was also no association between receptor expression of the tumor cells and Child-Pugh score or patient survival, and there was also no influence of patient age or gender.

A different picture emerged regarding SSTR5 and CXCR4 expression in tumor capillaries. HCCs displaying SSTR5-positive microvessels showed significantly higher Ki-67 values $(p=0.031)$ and more advanced grading $(p=0.023)$ compared to samples displaying no vascular SSTR5 expression. HCC patients with CXCR4-positive tumor capillaries exhibited significantly higher serum AFP values $(p=0.035)$ as well as a distinctly higher Ki-67 index $(p<0.001)$ than those with CXCR4-negative tumor microvessels. Moreover, overall survival of patients with HCC was significantly lower when CXCR4-positive tumor capillaries were present (log-rank test: $p=0.020$; Fig. 5). Also in CCC patients, CXCR4 positivity of tumor vessels was associated with an elevated Ki-67 index of the tumor $(p=0.037)$. Also here, patient overall survival was reduced when tumor vessels stained positive for CXCR4, although (probably due to the relatively small number of cases) statistical significance was not reached (log-rank test: $p=0.096$; Fig. 5). Between the SSTR5 or CXCR4 positivity of tumor microvessels and all other pathological or clinical parameters recorded no further significant association was found.

\section{Somatostatin and CXCR4 chemokine receptor expression} in human hepatoblastoma and hepatoma cell lines

Expression profiles of the SSTRs were quite divergent between the three hepatoblastoma and hepatoma cell lines investigated (Fig. 6). HepG2 cells displayed very weak expression of SSTR2 and moderate levels of 


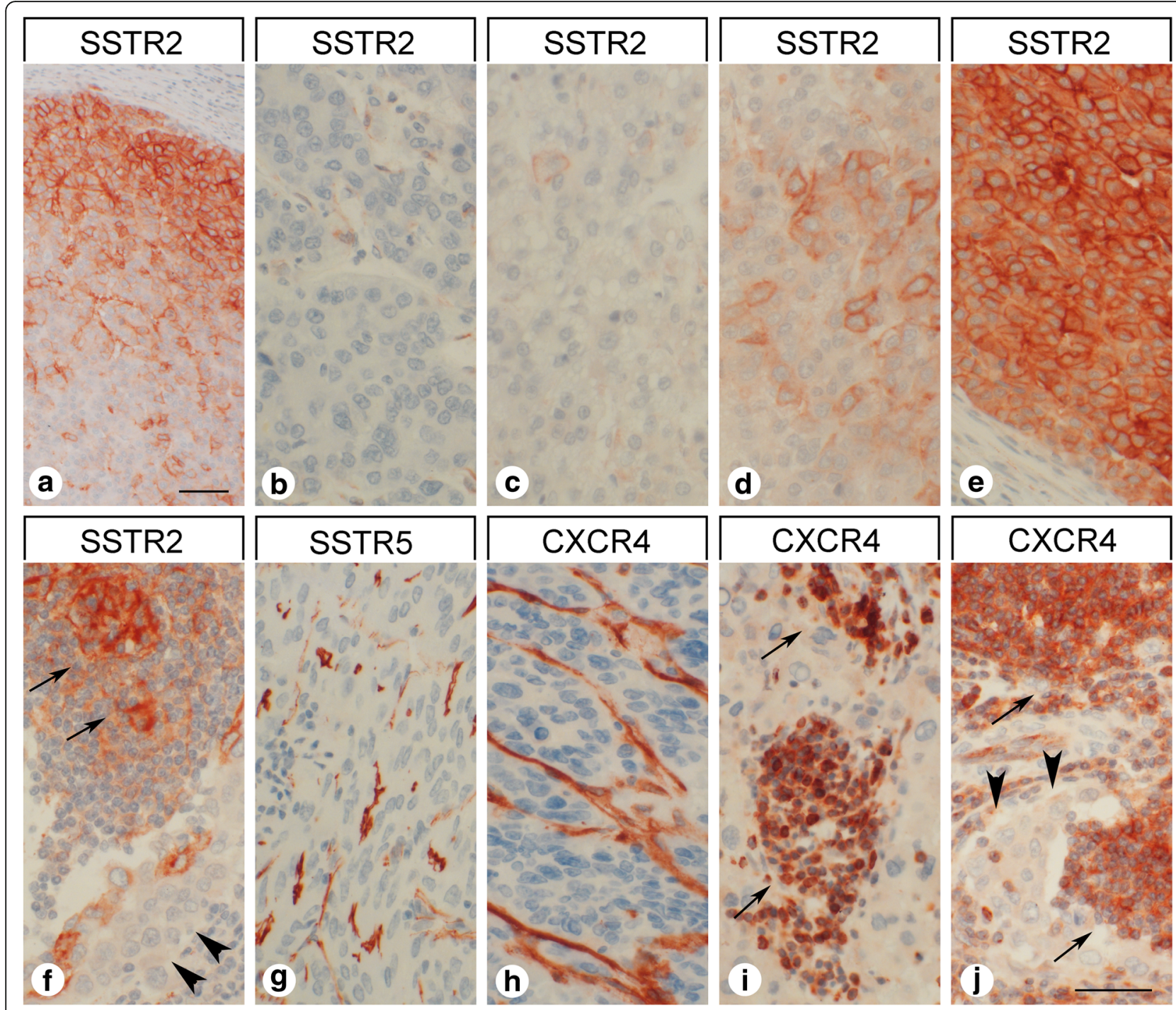

Fig. 4 Intraindividual variability in somatostatin receptor 2 (SSTR2) expression intensity in hepatocellular and cholangiocellular carcinomas and presence of somatostatin receptors (SSTR) and of CXCR4 in surrounding normal tissue and in tumor stroma. a-e Typical example for intraindividual variability of SSTR2 expression intensity in hepatocellular carcinomas. All photomicrographs were taken from the same tumor slide. Immunohistochemistry (red-brown color), counterstaining with hematoxylin; scale bar: A: $60 \mu \mathrm{m}, \mathrm{B}-\mathrm{E}: 50 \mu \mathrm{m}$. f, $\mathbf{j}$ Presence of SSTR2 and of CXCR4 in germinal centers of lymph follicles (arrows) in close vicinity to (largely negative) tumor cells (arrowheads). $\mathbf{g}, \mathbf{h}$ SSTR5 and CXCR4 expression in tumor vessels. i Strong CXCR4 staining of infiltrating lymphocytes (arrows). Immunohistochemistry (red-brown color), counterstaining with hematoxylin; scale bar: $50 \mu \mathrm{m}$

SSTR5. Hep3B cells showed very weak expression of SSTR3 in addition to SSTR2 and SSTR5 staining. In contrast, HuH-7 cells stained positive for SSTR1, SSTR2, and SSTR5, but not SSTR3. The small cell lung cancer cell line NCI-H69 was devoid of SSTR1 expression but strongly expressed SSTR2, SSTR3, and SSTR5 (Fig. 6). BON-1 cells displayed weak SSTR1, moderate SSTR2, very weak SSTR3, and strong SSTR5 staining (Fig. 6). In all cases, both membrane-bound and cytoplasmic staining was observed.

With respect to CXCR4, Hep3B and HuH-7 cells displayed very weak expression, whereas moderate or strong staining was observed in BON-1 and NCI-H69 cells, respectively. Also here, both membrane-bound and cytoplasmic CXCR4 staining was evident. In HepG2 cells, in contrast, no noticeable CXCR4 expression was detected (Fig. 6).

\section{Discussion}

\section{Patient characteristics}

There was a strong prevalence of male gender (ratio of male:female patients $=4: 1$ ) in our study population, which corresponds well with literature data on HCC and CCC $[9,59,60]$. Also, median age of the patients 

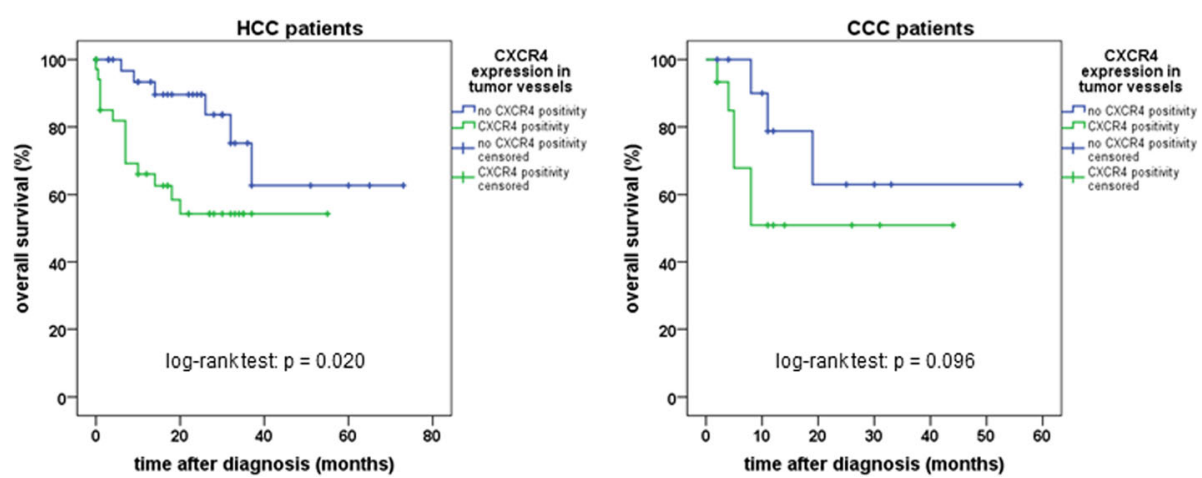

Fig. 5 Overall survival of HCC or CCC patients with either no CXCR4 expression ( $n=36$ [HCC] or 12 [CCC]) or with CXCR4 positive staining $(n=35$ $[\mathrm{HCC}]$ or $15[\mathrm{CCC}])$ of tumor capillaries

at diagnosis (65 years) was in good agreement with the literature $[9,60,61]$. The median survival of patients with HCC in our study (21 months) was somewhat higher than that described in epidemiological studies $[3,4]$. This difference may be due to the fact that we used tumor samples from patients who had undergone liver resection or liver transplantation, which usually implies a low tumor stage. Accordingly, the majority of our patients with HCC had stage I or stage II disease. In contrast, median survival of the patients with CCC was only half of that described in the literature [9], even though the patients in our study were subjected to surgical treatment.

\section{Somatostatin and CXCR4 chemokine receptor expression}

In contrast to the existing literature, we detected SSTRs only infrequently in our cohort of patients. Previous studies had reported expression of all SSTRs - with the exception of SSTR4 - in 40-75\% of HCCs, although sometimes with great variability and quite divergent receptor expression profiles [12-17]. Because at least moderately strong receptor expression intensity (i.e. an IRS $\geq 6$ ) is mandatory for clinical utility, our results indicate that very few patients with HCC (about 10\% of patients) are suited for SSTR-based diagnostics or therapy. This is in good agreement with the disappointing results of the majority of the trials to treat HCC using somatostatin analogs (see e.g. [29-36]). One reason for the

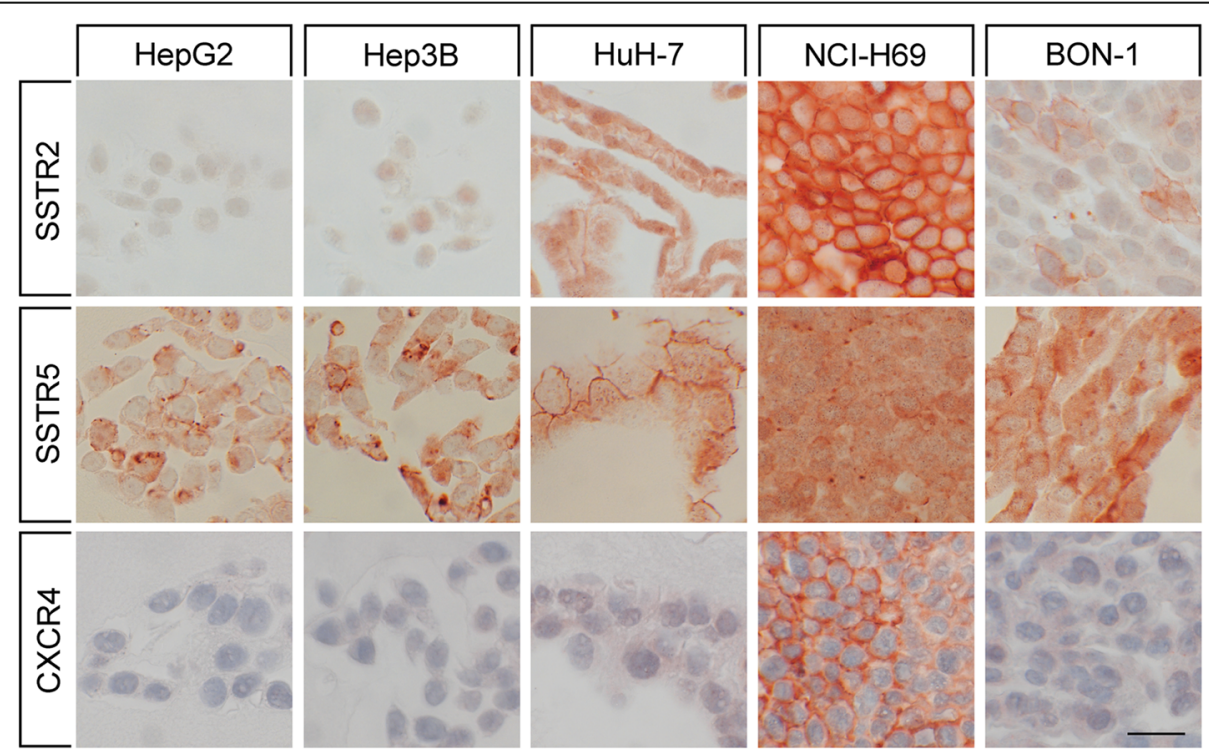

Fig. 6 Somatostatin receptor 2 (SSTR2), somatostatin receptor 5 (SSTR5) and CXCR4 expression in the hepatoblastoma cell line HepG2 and in the hepatoma cell lines Hep3B and HuH-7 in comparison to the small cell lung cancer cell line NCl-H69 and the neuroendocrine tumor cell line BON1. Immunohistochemistry (red-brown color), counterstaining with hematoxylin; scale bar: $20 \mu \mathrm{m}$. Representative photomicrographs of three independent batches are shown 
discrepancies between the immunohistochemical data in literature and our staining results may be that different antibodies have been used. Whereas in the present study well-characterized monoclonal antibodies were employed, the great majority of immunohistochemical investigations in literature have been performed with polyclonal antibodies from different commercial and non-commercial sources (which may also explain the great variability in the SSTR expression profiles described). We rated the staining by means of the IRS, taking both frequency and intensity of expression into account, and only samples displaying an IRS value $\geq 3$ were considered positive. Other studies provided no information to indicate which method was adopted to measure staining frequency and/or intensity. On the other hand, there may also be differences in tumor SSTR expression depending on the ethnicity of the patients and/or the etiology of the disease. The few trials reporting beneficial effects of somatostatin analogs in patients with $\mathrm{HCC}$ were either from Greece or Asia and comprised a high percentage of hepatitis $\mathrm{B}$ or $\mathrm{C}$ cases [16, 25-28]. This observation is mirrored by a meta-analysis [35] showing that octreotide has been ineffective in trials performed in Western countries but has significantly increased survival in Chinese studies with a high proportion of hepatitis B or C cases. Correspondingly, in an American study [34] no overall benefit of octreotide LAR in patients with HCC was observed, although one subgroup of patients showed significantly better survival than other subgroups. Some of the patients in that study were of Asian descent and had a history of hepatitis B infection. Our study included only Caucasians and only two of the 71 HCC patients had a history of hepatitis $B$ infection. However, in both of those patients, no SSTR or CXCR4 expression was present. Because the issue still remains to be resolved, further studies using well-characterized monoclonal antibodies in a much larger set of patients to compare different ethnicities, HCC etiologies, and histopathological subgroups are necessary in order to identify patient subgroups that may benefit from somatostatin analog therapy. In our HCC patient cohort with mainly alcohol-related liver disease, SSTRs were not expressed at substantial frequencies or levels. Thus, because of the high costs of lifelong injections of long-acting pan-somatostatin-analogs [62, 63], such treatments should not be regarded as a standard therapy in such patients.

Our study is the first to analyze CCCs for the prevalence of the different SSTR subtypes. Thirty percent of the CCC samples displayed moderately strong SSTR expression (SSTR1 in most cases). Hence and in contrast to HCC, CCC may be well suited for SSTR-based treatment. In such instances, however, pan-somatostatin analogs should be preferred.
In contrast to the generally low levels of SSTRs, CXCR4 was more prevalent in HCC samples, although few tumors (6\%) displayed moderately strong receptor expression. Similar to SSTRs, CXCR4 staining was more common in CCC than in HCC, and $11 \%$ of the samples displayed moderately strong CXCR4 expression. Again, there may also be differences in CXCR4 expression in HCC depending on the ethnicity of the patients and/or the etiology of the disease. In contrast, apart from a few positive Kupffer cells, normal liver tissues were largely devoid of CXCR4 expression, which is in agreement with the literature reporting higher CXCR4 expression in tumors compared with surrounding "normal" tissues [38-44].

The direct comparison of the receptor expression profiles between HCC and CCC (representing two different primary liver tumor entities with different etiologies) revealed a significantly higher SSTR1, SSTR2, SSTR5 and CXCR4 expression in CCC as compared to HCC. The most striking difference was seen with respect to SSTR1 expression. Whereas in HCC SSTR1 was expressed only in a very few cases, $67 \%$ of the CCC showed an IRS value $\geq 3$ points. Thus, SSTR1 could serve as an additional marker to distinguish $\mathrm{HCC}$ from $\mathrm{CCC}$ and to identify the CCC portion in mixed tumors.

Neo-angiogenesis is an important factor in tumor growth, progression, and metastasis. Thus, targeting of angiogenic pathways has proven to have antitumor effects in a variety of cancers [64]. Because HCCs are highly vascularized tumors, they represent good candidates for antiangiogenic therapy. In HCC, however, the multi-tyrosine kinase inhibitor sorafenib displays only moderate effects in most patients and is not considered curative [65]. Furthermore, almost all clinical studies with other multi-tyrosine kinase inhibitors have failed [66]. Therefore, alternative antiangiogenic substances are currently under investigation for use in $\mathrm{HCC}$ treatment. In $\mathrm{CCC}$, no respective treatment option currently exists. We found that CXCR4 was intensely expressed on tumor vessels in about $50 \%$ of both HCCs and CCCs. In HCC, CXCR4 staining of the tumor vessels was significantly associated with poor patient outcomes. A similar tendency was seen also in CCC. The presence of CXCR4 on endothelial cells in HCC has been observed previously [39, 47], although there was no association with tumor stage or grade, and specific targeting of the CXCL12/CXCR4 axis as an antiangiogenic strategy in $\mathrm{HCC}$ was recently suggested [67]. For CCC, similar observations have not been made so far. Although CXCR4 was not substantially expressed by HCC or CCC tumor cells, the distinct presence of CXCR4 on tumor capillaries in many cases may open up new possibilities to indirectly target such tumors by depriving them of their supportive environment. 
Somatostatin and CXCR4 chemokine receptor expression in human hepatoblastoma and hepatoma cell lines In literature, SSTR expression in human hepatoblastoma or hepatoma cell lines has most often been evaluated in HepG2 cells. Previous studies observed expression of SSTR2 [13, 18, 68, 69], SSTR5 [13, 68], and SSTR3 [13, 18, 68] in HepG2 cells. Hep3B cells were not previously investigated with respect to SSTR expression. In $\mathrm{HuH}-7$ cells (as in our experiments) previous studies reported expression of SSTR1, SSTR2, and SSTR5, but not that of SSTR3 [13]. Overall, our data on SSTR expression in these hepatoblastoma/hepatoma cell lines fit well with expression patterns obtained from HCC tumor staining. Similar to the results for the HCC samples, the most prominent SSTR in the hepatoblastoma/hepatoma cell lines was SSTR5, and (as in the tumors) expression of SSTRs in hepatoblastoma/hepatoma cell lines was weak compared with the expression levels observed in NCI-H69 and BON-1 cells.

With respect to CXCR4 expression, our results confirm previous findings showing CXCR4 expression in Hep3B and HuH-7 cells [43, 44, 70-72]. Regarding HepG2 cells, data in literature are controversial. While some authors were able to demonstrate CXCR4 expression [70-72], others were not [44]. According to our findings, all three hepatoblastoma/hepatoma cell lines only weakly expressed CXCR4 compared to NCI-H69 cells, which, again, fits well with our HCC staining results.

\section{Conclusions}

In our study population, $\mathrm{CCC}$, but not $\mathrm{HCC}$, may be suited for both SSTR- and CXCR4-based treatment attempts. Because of the predominant expression of SSTR1, pan-somatostatin analogs should be preferred. In both $\mathrm{HCC}$ and $\mathrm{CCC}$, indirect targeting of the tumors via the CXCR4 expressed on the tumor capillaries may represent an additional promising therapeutic strategy.

\section{Additional file}

Additional file 1: Figure S1. Positive controls for immunostainings.

Typical examples for positive control immunostainings for somatostatin receptors (SSTR) and CXCR4. SSTR1, SSTR2, SSTR3 and SSTR5: pancreatic islets; SSTR4: human cortex; CXCR4: germinal center of a lymph node. Immunohistochemistry (red-brown color), counterstaining with hematoxylin; scale bar: $20 \mu \mathrm{m}$. (TIFF $16836 \mathrm{~kb}$ )

\section{Abbreviations}

CCC: Cholangiocellular carcinoma; HCC: Hepatocellular carcinoma; SSTR: Somatostatin receptor

Acknowledgements

Not applicable

\section{Funding}

The Theranostic Research Center, Zentralklinik Bad Berka, 99,437 Bad Berka, Germany, provided funding for this research. The funding body had no influence on the design of the study and on the collection, analysis, and interpretation of the data and on writing of the manuscript.

\section{Availability of data and materials}

The datasets used and/or analysed during the current study are available from the corresponding author on reasonable request.

\section{Authors' contributions}

Conceived and designed the experiments: SS, UD, DK, AL. Provided the tumor samples: UD, OD, JS. Provided the antibodies: SS. Acquired the clinical data: DK, AAH. Performed the experiments: RS, FM, AL. Analyzed the data: RS, FM, AL. Interpreted the data: AL. Wrote the manuscript: AL. Revised critically the manuscript: DK, UD, OD, JS, SS, AAH, RS, FM. Gave the final approval to the version to be published: DK, UD, OD, JS, SS, AAH, RS, FM, AL. All authors have read and approved the final version of the manuscript. Each of the authors acknowledges that he or she participated sufficiently in the work to take public responsibility for its content and each of the authors agreed to be accountable for all aspects of the work in ensuring that questions related to the accuracy or integrity of any part of the work are appropriately investigated and resolved.

\section{Ethics approval and consent to participate}

All procedures performed in this study involving human participants were in accordance with the 1964 Helsinki declaration and its later amendments. Permission was gained from the local ethics committee (Ethikkommission der Landesärztekammer Thüringen) for this retrospective analysis. Written informed consent for the use of tissue samples for scientific purposes was obtained from all individual participants included in the study when entering the Theranostic Research Center, Zentralklinik Bad Berka, Bad Berka, Germany, and the Department of General, Visceral and Vascular Surgery, Jena

University Hospital, Jena, Germany. All data were analyzed anonymously.

\section{Consent for publication}

Not applicable

\section{Competing interests}

Daniel Kaemmerer received funding and support for travelling to meetings by the companies IPSEN and PFIZER. All other authors declare that there is no conflict of interest that could be perceived as prejudicing the impartiality of the research reported.

\section{Publisher's Note}

Springer Nature remains neutral with regard to jurisdictional claims in published maps and institutional affiliations.

\section{Author details}

${ }^{1}$ Department of General and Visceral Surgery, Zentralklinik Bad Berka, Bad Berka, Germany. ${ }^{2}$ Institute of Pharmacology and Toxicology, Jena University Hospital, Friedrich Schiller University Jena, Drackendorfer Str. 1, D-07747 Jena, Germany. ${ }^{3}$ Department of General, Visceral and Vascular Surgery, Jena University Hospital, Jena, Germany. ${ }^{4}$ Institute of Pathology, Jena University Hospital, Jena, Germany. ${ }^{5}$ Institute of Pathology and Cytology Bad Berka, Bad Berka, Germany.

Received: 2 December 2016 Accepted: 13 December 2017

Published online: 28 December 2017

\section{References}

1. Gomez D, Lobo DN. Malignant liver tumours. Surgery. 2011;29:632-9.

2. Torre LA, Bray F, Siegel RL, Ferlay J, Lortet-Tieulent J, Jemal A. Global cancer statistics, 2012. CA Cancer J Clin. 2015;65:87-108.

3. Greten TF, Papendorf F, Bleck JS, Kirchhoff T, Wohlberedt T, Kubicka S, Klempnauer J, Galanski M, Manns MP. Survival rate in patients with hepatocellular carcinoma: a retrospective analysis of 389 patients. $\mathrm{Br} J$ Cancer. 2005:92:1862-8.

4. Altekruse SF, McGlynn KA, Reichman ME. Hepatocellular carcinoma incidence, mortality, and survival trends in the United States from 1975 to 2005. J Clin Oncol. 2009;27:1485-91. 
5. De Lope CR, Tremosini S, Forner A, Reig M, Bruix J. Management of HCC J Hepatol. 2012;56:75-87.

6. Zhai B, Sun XY. Mechanisms of resistance to sorafenib and the corresponding strategies in hepatocellular carcinoma. World J Hepatol. 2013;5:345-52.

7. Chen J, Jin R, Zhao J, Liu J, Ying H, Yan H, Zhou S, Liang Y, Huang D, Liang $X$, Hong $Y$, Lin $H$, Cai X. Potential molecular, cellular and microenvironmental mechanism of sorafenib resistance in hepatocellular carcinoma. Cancer Lett. 2015;367:1-11.

8. Bergquist A, von Seth E. Epidemiology of cholangiocarcinoma. Best Pract Res Clin Gastroenterol. 2015;29:221-32.

9. Kim Y, Moris DP, Zhang XF, Bagante F, Spolverato G, Schmidt C, Dilhoff M, Pawlik TM. Evaluation of the 8th edition American joint commission on cancer (AJCC) staging system for patients with intrahepatic cholangiocarcinoma: a surveillance, epidemiology, and end results (SEER) analysis. J Surg Oncol. 2017; https://doi.org/10.1002/jso.24720.

10. Razumilava N, Gores GJ. Classification, diagnosis, and management of cholangiocarcinoma. Clin Gastroenterol Hepatol. 2013;11:13-e4.

11. Schweizer N, Vogel A. Systemic therapy of cholangiocarcinoma: from chemotherapy to targeted therapies. Best Pract Res Clin Gastroenterol. 2015; 29:345-53.

12. Blaker M, Schmitz M, Gocht A, Burghardt S, Schulz M, Broring DC, Pace A, Greten $\mathrm{H}$, de Weerth A. Differential expression of somatostatin receptor subtypes in hepatocellular carcinomas. J Hepatol. 2004;41:112-8.

13. Reynaert $H$, Rombouts $K$, Vandermonde A, Urbain D, Kumar U, Bioulac-Sage P, Pinzani M, Rosenbaum J, Geerts A. Expression of somatostatin receptors in normal and cirrhotic human liver and in hepatocellular carcinoma. Gut. 2004;53:1180-9.

14. Xie YM, Yan LN, Wei B, Guo MM, Tang CW. Correlation of somatostatin receptor expression in human hepatocellular carcinoma tissue to serum alpha-fetoprotein concentration. Chin J Cancer. 2007;26:688-92.

15. Verhoef $\mathrm{C}$, van Dekken $\mathrm{H}$, Hofland $L J$, Zondervan $\mathrm{PE}$, de Wilt JHW, van Marion R, de Man RA, IJzermans JNM, van Eijck CHJ. Somatostatin receptor in human hepatocellular carcinomas: biological, patient and tumor characteristics. Dig Surg. 2008;25:21-6.

16. Li S, Liu Y, Shen Z. Characterization of somatostatin receptor 2 and 5 expression in operable hepatocellular carcinomas. Hepato-Gastroenterol. 2012:59:2054-8

17. Koc EU, Ozgur T, Yerci O, Gurel S. Somatostatin receptor 1 (SSTR1) and somatostatin receptor 5 (SSTR5) expression in hepatocellular carcinoma. Hepato-Gastroenterol. 2013;60:1693-7.

18. Liu HL, Huo L, Wang L. Octreotide inhibits proliferation and induces apoptosis of hepatocellular carcinoma cells. Acta Pharmacol Sin. 2004;25 $1380-6$.

19. Jia WD, Xu GL, Wang W, Wang ZH, Li JS, Ma JL, Ren WH, Ge YS, Yu JH, Liu WB. A somatostatin analogue, octreotide, inhibits the occurrence of second primary tumors and lung metastasis after resection of hepatocellular carcinoma in mice. Tohoku J Exp Med. 2009;218:155-60.

20. Hua YP, Yin XY, Peng BG, Li SQ, Lai JM, Liang HZ, Ling L. Mechanisms and influence of octreotide-induced regulation of somatostatin receptor 2 on hepatocellular carcinoma. Chemother. 2009:55:312-20.

21. Borbath I, Starkel P. Chemoprevention of hepatocellular carcinoma: proof of concept in animal models. Acta Gastroenterol Belg. 2011;74:34-44.

22. Tsagarakis NJ, Drygiannakis I, Batistakis AG, Kolios G, Kouroumalis EA. Octreotide induces caspase activation and apoptosis in human hepatoma HepG2 cells. World J Gastroenterol. 2011;17:313-21.

23. Xie Y, Chen S, Wang $\mathrm{CH}$, Tang CW. SOM230 combined with celecoxib prolongs the survival in nude mice with HepG-2 xenografts. Cancer Biol Ther 2011:12:86-92.

24. Abdel-Hamid NM, Mohafez OM, Nazmy MH, Farhan A, Thabet K. The effect of co-administration of Lawsonia Inermis extract and octreotide on experimental hepatocellular carcinoma. Environ Health Prev Med. 2015;20: 195-203.

25. Samonakis DN, Moschandreas J, Arnaoutis T, Skordilis P, Leontidis C, Vafiades I, Kouroumalis E. Treatment of hepatocellular carcinoma with long acting somatostatin analogues. Oncol Rep. 2002;9:903-7.

26. Gill ML, Atiq M, Sattar S, Khokar N. Treatment outcomes with long acting octreotide in inoperable hepatocellular carcinoma: a local experience and review of literature. J Pak Med Assoc. 2005;55:135-8.

27. Dimitroulopoulos D, Xinopoulos D, Tsamakidis K, Zisimopoulos A, Andriotis E, Panagiotakos D, Fotopoulou A, Chrysohoou C, Bazinis A, Daskalopoulou D,
Paraskevas E. Long acting octreotide in the treatment of advanced hepatocellular cancer and overexpression of somatostatin receptors: randomized placebo-controlled trial. World J Gastroenterol. 2007;13:3164-70.

28. Borbath I, Lhommel R, Guiot Y, Coche E, Sempoux C. Lanreotide treatment of metastatic hepatocellular carcinoma resulting in partial regression and more than 3 years of progression-free survival. Acta Gastroenterol Belg. 2012;75:270-3

29. Cebon J, Australasian Gastro-Intestinal Trials Group (AGITG) AG000I H Investigators. Somatostatin receptor expression, tumor response, and quality of life in patients with advanced hepatocellular carcinoma treated with long-acting octreotide. Br J Cancer. 2006;95:853-61.

30. Becker G, Allgaier HP, Olschewski M, Zahringer A, Blum HE. Hector study group. Long-acting octreotide versus placebo for treatment of advanced HCC: a randomized controlled double-blind study. Hepatology. 2007:45:9-15.

31. Farinati F, Sergio A, Baldan A, Zucchetta P, Corleto VD. Octreotide and hepatocellular carcinoma. Br J Cancer. 2007;96:1778-9.

32. Verset G, Verslype C, Reynaert H, Borbath I, Langlet P, Vandebroek A, Peeters M, Houbiers G, Francque S, Arvanitakis M, Van Laethem JL. Efficacy of the combination of long-acting release octreotide and tamoxifen in patients with advanced hepatocellular carcinoma: a randomised multicentre phase III study. Br J Cancer. 2007:97:582-8.

33. Barbare JC, Bouche O, Bonnetain F, Dahan L, Lombard-Bohas C, Faroux R, Raoul JL, Cattan S, Lemoine A, Blanc JF, Bronowicki JP, Zarski JP, Cazorla S, Gargot D, Thevenot T, Diaz E, Bastie A, Aparicio T, Bedenne L. Treatment of advanced hepatocellular carcinoma with long-acting octreotide: a phase III multicenter, randomized, double blind placebo-controlled study. Eur J Cancer. 2009:45:1788-97.

34. Shah U, O'Neil B, Allen J, Goldberg RM, Bernard S, Moore D, Venook AP, Morse MM. A Phase II study of long-acting octreotide in patients with advanced hepatocellular carcinoma and CLIP score of 3 or higher. Gastrointest Cancer Res. 2009;3:45-8.

35. Ji XQ, Ruan XJ, Chen H, Chen G, Li SY, Yu B. Somatostatin analogues in advanced hepatocellular carcinoma: an updated systematic review and meta-analysis of randomized controlled trials. Med Sci Monit. 2011;17: RA169-76.

36. Sanoff HK, Kim R, Ivanova A, Alistar A, McRee AJ, O'Neil BH. Everolimus and pasireotide for advanced and metastatic hepatocellular carcinoma. Investig New Drugs. 2015;33:505-9.

37. Zhao H, Guo L, Zhao H, Zhao J, Weng H, Zhao B. CXCR4 over-expression and survival in cancer: A system review and meta-analysis. Oncotarget. 2015;6:5022-40.

38. Schimanski CC, Bahre R, Gockel I, Müller A, Frerichs K, Hörner V, Teufel A, Simiantonaki N, Biesterfeld S, Wehler T, Schuler M, Achenbach T, Junginger $\mathrm{T}$, Galle PR, Moehler M. Dissemination of hepatocellular carcinoma is mediated via chemokine receptor CXCR4. Br J Cancer. 2006;95:210-7.

39. Li W, Gomez E, Zhang Z. Immunohistochemical expression of stromal cellderived factor-1 (SDF-1) and CXCR4 ligand receptor system in hepatocellular carcinoma. J Exp Clin Cancer Res. 2007;26:527-33.

40. Liu H, Pan Z, Li A, Fu S, Lei Y, Sun H, Wu M, Zhou W. Roles of chemokine receptor 4 (CXCR4) and chemokine ligand 12 (CXCL12) in metastasis of hepatocellular carcinoma cells. Cell Mol Immunol. 2008:5:373-8.

41. Xiang ZL, Zeng ZC, Tang ZY, Fan J, Zhuang PY, Liang Y, Tan YS, He J. Chemokine receptor CXCR4 expression in hepatocellular carcinoma patients increases the risk of bone metastasis and poor survival. BMC Cancer. 2009;9:176.

42. Hu F, Miao L, Zhao Y, Xiao YY, Xu Q. A meta-analysis for C-X-C chemokine receptor type 4 as a prognostic marker and potential drug target in hepatocellular carcinoma. Drug Des Dev Ther. 2015;9:3625-33.

43. Liu H, Liu Y, Liu W, Zhang W, Xu J. EZH2-mediated loss of miR-622 determines CXCR4 activation in hepatocellular carcinoma. Nat Commun. 2015;6:8494.

44. Polimeno MN, lerano C, D'Alterio C, Losito NS, Napolitano M, Portella L, Scognamiglio G, Tatangelo F, Trotta AM, Curley S, Costantini S, Liuzzi R, Izzo F, Scala S. CXCR4 expression affects overall survival of HCC patients whereas CXCR7 expression does not. Cell Mol Immunol. 2015;12:474-82.

45. Rubie C, Frick VO, Wagner M, Weber C, Kruse B, Kempf K, König J, Rau B, Schilling M. Chemokine expression in hepatocellular carcinoma versus colorectal liver metastases. World J Gastroenterol. 2006;12:6627-33.

46. Monnier J, Boissan M, L'Helgoualc'h A, Lacombe ML, Turlin B, Zucman-Rossi J, Theret N, Piquet-Pellorce C, Samson M. CXCR7 is up-regulated in human and murine hepatocellular carcinoma and is specifically expressed by endothelial cells. Eur J Cancer. 2012;48:138-48. 
47. Shibuta K, Mori M, Shimoda K, Inoue H, Mitra P, Barnard GF. Regional expression of CXCL12/CXCR4 in liver and hepatocellular carcinoma and cellcycle variation during in vitro differentiation. Jpn. Cancer Res. 2002;93:789-97.

48. Li N, Guo W, Shi J, Xue J, Hu H, Xie D, Wu M, Cheng S. Expression of the chemokine receptor CXCR4 in human hepatocellular carcinoma and its role in portal vein tumor thrombus. J Exp Clin Cancer Res. 2010:29:156.

49. Zhao S, Wang J, Qin C. Blockade of CXCL12/CXCR4 signaling inhibits intrahepatic cholangiocarcinoma progression and metastasis via inactivation of canonical Wnt pathway. J Exp Clin Cancer Res. 2014;33:103.

50. Fischer T, Doll C, Jacobs S, Kolodziej A, Stumm R, Schulz S. Reassessment of sst2 somatostatin receptor expression in human normal and neoplastic tissues using the novel rabbit monoclonal antibody UMB-1. J Clin Endocrinol Metab. 2008a;93:4519-24.

51. Fischer T, Nagel F, Jacobs S, Stumm R, Schulz S. Reassessment of CXCR4 chemokine receptor expression in human normal and neoplastic tissues using the novel rabbit monoclonal antibody UMB-2. PLoS One. 2008b;3: e4069.

52. Lupp A, Hunder A, Petrich A, Nagel F, Doll C, Schulz S. Reassessment of sst5 somatostatin receptor expression in normal and neoplastic human tissues using the novel rabbit monoclonal antibody UMB-4. Neuroendocrinology. 2011:94:255-64.

53. Lupp A, Nagel F, Doll C, Röcken C, Evert M, Mawrin C, Saeger W, Schulz S. Reassessment of sst3 somatostatin receptor expression in normal and neoplastic human tissues using the novel rabbit monoclonal antibody UMB4. Neuroendocrinology. 2012;96:301-10.

54. Lupp A, Nagel F, Schulz S. Reevaluation of sst1 somatostatin receptor expression in human normal and neoplastic tissues using the novel rabbit monoclonal antibody UMB-7. Regul Pept. 2013;183:1-6.

55. Lambertini C, Barzaghi-Rinaudo P, D'Amato L, Schulz S, Nuciforo P, Schmid HA. Evaluation of somatostatin receptor subtype expression in human neuroendocrine tumors using two sets of new monoclonal antibodies. Regul Pept. 2013;187:35-41.

56. Chinezu L, Vasiljevic A, Jouanneau E, François P, Borda A, Trouillas J, Raverot $\mathrm{G}$. Expression of somatostatin receptors, SSTR2A and SSTR5, in 108 endocrine pituitary tumors using immunohistochemical detection with new specific monoclonal antibodies. Hum Pathol. 2014:45:71-7.

57. Kaemmerer D, Sänger J, Arsenic R, D'Haese JG, Neumann J, Schmitt-Graeff A, Wirtz RM, Schulz S, Lupp A. Evaluation of somatostatin, CXCR4 chemokine and endothelin a receptor expression in a large set of paragangliomas. Oncotarget. 2017; https:/doi.org/10.18632/oncotarget.21194.

58. Remmele W, Stegner HE. Recommendation for uniform definition of an immunoreactive score (IRS) for immunohistochemical estrogen receptor detection (ER-ICA) in breast cancer tissue. Pathologe. 1987;8:138-40.

59. El-Serag HB, Rudolph KL. Hepatocellular carcinoma: epidemiology and molecular carcinogenesis. Gastroenterology. 2007;132:2557-76.

60. Khan SA, Toledano MB, Taylor-Robinson SD. Epidemiology, risk factors, and pathogenesis of cholangiocarcinoma. HPB. 2008;10:77-82

61. Borzio M, Dionigi E, Parisi G, Raguzzi I, Sacco R. Management of hepatocellular carcinoma in the elderly. World J Hepatol. 2015;18:1521-9.

62. Biermasz NR, Roelfsema F, Pereira AM, Romijn JA. Cost-effectiveness of lanreotide autogel in treatment algorithms of acromegaly. Expert Rev Pharmacoeon Outcomes Res. 2009;9:223-34.

63. Roset M, Merino-Montero S, Luque-Ramirez M, Webb SM, Lopez-Mondejar P, Salinas I, Soto A, Bernal C, Villabona C, De Luis D, Donnay S, Pascual H, Perez-Luis J, Spanish group of the OASIS study. Cost of clinical management of acromegaly in Spain. Clin Drug Investig. 2012;32:235-45.

64. Folkman J. Angiogenesis: an organizing principle for drug discovery? Nat Rev Drug Discov. 2007;6:273-86.

65. Llovet JM, Ricci S, Mazzaferro V, Hilgard P, Gane E, Blanc JF, de Oliveira AC, Santoro A, Raoul JL, Forner A, Schwartz M, Porta C, Zeuzem S, Bolondi L, Greten TF, Galle PR, Seitz JF, Borbath I, Häussinger D, Giannaris T, Shan M, Moscovici M, Voliotis D, Bruix J, SHARP Investigators Study Group. Sorafenib in advanced hepatocellular carcinoma. N Engl J Med. 2008;359:378-90.

66. Moriguchi M, Umemura A, Itoh Y. Current status and future prospects of chemotherapy for advanced hepatocellular carcinoma. Clin J Gastroenterol. 2016;9:184-90

67. Guo F, Wang Y, Liu J, Mok SC, Xue F, Zhang W. CXCL12/CXCR4: a symbiotic bridge linking cancer cells and their stromal neighbors in oncogenic communication networks. Oncogene 2016;35:816-826.

68. Notas G, Kolios G, Mastrodimou N, Kampa M, Vasilaki A, Xidakis C, Castanas E, Thermos K, Kouroumalis E. Cortistatin production by HepG2 human hepatocellular carcinoma cell line and distribution of somatostatin receptors. J Hepatol. 2004;40:792-8.

69. Li Y, Si JM, Zhang S, Du J, Wang F, Jia B. Somatostatin receptor subtype 2mediated scintigraphy and localization using 99mTc-HYNIC-Tyr3-octreotide in human hepatocellular carcinoma-bearing nude mice. World J Gastroenterol. 2005;11:3953-7.

70. Kim SW, Kim HY, Song IC, Jin SA, Lee HJ, Yun HJ, Kim S, Jo DY. Cytoplasmic trapping of CXCR4 in hepatocellular carcinoma cell lines. Cancer Res Treat. 2008;40:53-61.

71. Bertran E, Crosas-Molist E, Sancho P, Caja L, Lopez-Luque J, Navarro E, Egea G, Lastra R, Serrano T, Ramos E, Fabregat I. Overactivation of the TGF- $\beta$ pathway confers a mesenchymal-like phenotype and CXCR4-dependent migratory properties to liver tumor cells. Hepatology 2013;58:2032-2044.

72. Li X, Li P, Chang Y, Xu Q, Wu Z, Ma Q, Wang Z. The SDF/CXCR4 axis induces epithelial-mesenchymal transition in hepatocellular carcinoma. Mol Cell Biochem. 2014;392:77-84.

\section{Submit your next manuscript to BioMed Central and we will help you at every step:}

- We accept pre-submission inquiries

- Our selector tool helps you to find the most relevant journal

- We provide round the clock customer support

- Convenient online submission

- Thorough peer review

- Inclusion in PubMed and all major indexing services

- Maximum visibility for your research

Submit your manuscript at www.biomedcentral.com/submit
Biomed Central 